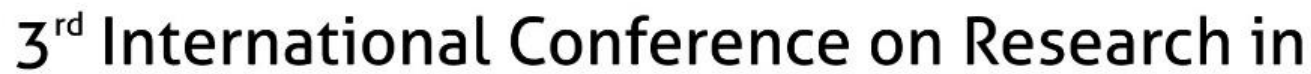 EDUCATION
}

\section{Erasmus+ as a Vehicle for Change in CLIL School Contexts}

\author{
Enrique Ruiz Cano \\ CEIP Ntra. Sra. de la Fuensanta \& Nebrija University, Spain
}

\begin{abstract}
I believe that schools of the future must become open learning communities. Not only for students, but also for employees. It is important schools enable teachers to develop professionally and personally, not only domestically but also nationally and internationally. As a result, we began to look for ways to systematically monitor changes in our established practices that would indicate the professional and personal development of employees as a consequence of international experience.
\end{abstract}

Throughout this talk/seminar, I will lay out the benefits that an Erasmus+ project can bring about for a CLIL school regarding teachers and pupils. We will look at specific examples of different CLIL schools across Europe (Spain, Italy, and Latvia) and see how the CLIL teaching practice can change for the better in terms of making staff more broad-minded. I will also bring to the fore some benefits from an intercultural and linguistic perspective and I will also look into the concept of "Culture" in CLIL and what that entails from a pedagogical point of view (Schulz 2001; Ellis 2003; Yamada 2019; Kinginger 2013).

What is more, I will draw up a relationship between intercultural competence and language based on the research we have carried out during an Erasmus+ KA201 project in which Spain, Italy and Latvia participated. During this research, we got very interesting results which went to show that CLIL children's direct involvement in an Erasmus + project can significantly increase their intercultural awareness and linguistic competence in the target language and therefore, outperform other CLIL learners who are not involved in European projects. During the development of this conference, I will put forward these results e.g. enhancement of the teaching practice, increased children's intercultural awareness, etc. and give further details about the benefits that the participation in Erasmus+ projects has for CLIL learners.

Key Words: Erasmus+, interculturality, intercultural competence, linguistic competence, target language, CLIL, language and culture adquisition/learning. 